\title{
Desempenho e características de carcaça de tourinhos mestiços terminados em confinamento com dietas à base de cana-de-açúcar em substituição à silagem de sorgo
}

\author{
Andréa Pereira Pinto ${ }^{1}$, José Jorge dos Santos Abrahão², Jair de Araújo Marques ${ }^{3}$, Willian \\ Gonçalves do Nascimento ${ }^{4}$, Daniel Perotto ${ }^{5}$, Simony Marta Bernardo Lugão ${ }^{2}$
}

\footnotetext{
1 Universidade Federal do Ceará - UFC, Departamento de Zootecnia, CEP: 60356-901, Fortaleza, CE.

2 IAPAR, Caixa postal 564, CEP: 87701-970, Paranavaí, PR.

3 Universidade Federal do Recôncavo da Bahia - UFRB, CCAAB, CEP: 44380-000, Cruz das Almas, BA.

${ }^{4}$ Universidade Federal Rural de Pernambuco - UFRPE, Departamento de Zootecnia, CEP: 55.296-190, Garanhuns, PE.

${ }^{5}$ IAPAR - Pólo Regional de Curitiba.
}

\begin{abstract}
RESUMO - Objetivou-se estudar a utilização da cana-de-açúcar com dois níveis de concentrado em substituição à silagem de sorgo no confinamento de tourinhos mestiços. Utilizaram-se 36 tourinhos alojados em baias individuais, em delineamento inteiramente casualizado, com três dietas: silagem de sorgo + concentrado na quantidade de 1,0\% do peso vivo (PV), canade-açúcar picada + concentrado $(1,0 \% \mathrm{PV})$ e cana-de-açúcar picada + concentrado $(1,2 \% \mathrm{PV})$. As dietas foram calculadas para que tivessem em torno de $12 \%$ de proteína bruta. As dietas não promoveram diferença no rendimento de carcaça, na conversão alimentar e nas porcentagens de músculo, osso e gordura. O ganho médio diário e o índice bionutricional foram maiores nos animais alimentados com silagem de sorgo (1,70 kg e 13,12, respectivamente). O peso final e as ingestões de matéria seca, proteína bruta, fibra em detergente neutro e nutrientes digestíveis totais foram maiores nos animais alimentados com silagem de sorgo. A substituição de silagem de sorgo por cana-de-açúcar reduz o desempenho dos animais, mesmo quando fornecido maior nível de concentrado na dieta.
\end{abstract}

Palavras-chave: consumo, conversão alimentar, espessura de gordura subcutânea, ganho médio diário, ruminantes

\section{Performance and carcass characteristics of crossbred young bulls finished in a feedlot on diets with sorghum silage substituted by sugar cane}

\begin{abstract}
The experiment was conducted to evaluate the use of sugar cane at two concentrate levels as a replacement for sorghum silage in the diet of crossbred young bulls in feedlot. Thirty-six young crossbred males were maintained in individual stalls in a randomized complete experimental design with three diets: sorghum silage with $1.0 \%$ of the live weight (LW) in concentrate, sugar cane with concentrate $(1.0 \% \mathrm{LW})$ and sugar cane with concentrate $(1.2 \% \mathrm{LW})$. The diets were calculated to have approximately $12 \%$ crude protein. The diets did not cause differences in the dressing percentage, feed conversion and bone, muscle and fat percentage. The daily gains and bio-nutritional index were higher for the animals fed with sorghum silage (1.70 kg and 13.12, respectively). The final weight and ingestions of dry matter, crude protein, neutral detergent fiber and total digestible nutrients were higher for the animals fed sorghum silage. The replacement of sorghum silage with sugar cane reduce the animal performance, even when a higher level of concentrate is supplied in the diet.
\end{abstract}

Key Words: backfat thickness, daily weight gain, feed conversion, intake, ruminant

\section{Introdução}

No período da seca, quando a oferta de pastagens é escassa, utiliza-se o sistema de confinamento de bovinos; entretanto, para que esta atividade seja economicamente viável, torna-se necessária a utilização de alimentos alternativos que possam substituir os tradicionais como a silagem de milho, levando, com isso, a uma redução dos custos de produção.
Para substituir a silagem de milho, pode-se utilizar silagem de sorgo ou cana-de-açúcar picada; entretanto, como o valor energético da cana-de-açúcar é inferior ao da silagem, é necessário ajustar a dieta com concentrado para que se obtenha desempenho similar ao obtido com outros volumosos.

O sorgo é uma planta que pode ser comparada ao milho, devido às suas características agronômicas e ao valor 
nutritivo; portanto, torna-se uma alternativa interessante, uma vez que é mais resistente à seca, por sua capacidade de recuperar-se e produzir grãos após um período de estiagem (Rodrigues et al., 2002). Devido a estas características o potencial de produção de matéria seca é superior ao do milho em regiões sujeitas a períodos de estresse hídrico. A utilização de outras culturas como o sorgo, segundo Zago (1999), reduz os custos de produção e o ponto ideal de colheita é aquele em que a planta possui máximo teor de matéria seca, assegurando boa compactação e bom processo de fermentação. Portanto, o sorgo é ensilado no estádio de grão pastoso a farináceo, quando a planta apresenta entre 27 e $38 \%$ de MS.

Outro alimento utilizado de forma estratégica na alimentação dos animais ruminantes é a cana-de-açúcar. Em revisão realizada por Pinto et al. (2003), a cana-deaçúcar se destaca como volumoso de baixo custo, elevada produção de energia por unidade de área cultivada, fácil cultivo e pela manutenção do valor nutritivo por longo tempo após a maturação. Além disso, apresenta grande quantidade de carboidratos solúveis que são rapidamente fermentados no rúmen. A produtividade média da cana pode variar de 80 toneladas de matéria natural por hectare para a cana industrial a 55 toneladas de matéria natural por hectare para a cana com fins forrageiros, dependendo da fertilidade do solo e dos tratos culturais.

Este trabalho foi realizado com o objetivo de avaliar a substituição da silagem de sorgo por cana-de-açúcar na alimentação de tourinhos mestiços em terminação, confinados, utilizando-se dois níveis de concentrado com a cana-de-açúcar.

\section{Material e Métodos}

O experimento foi realizado no setor de confinamento, do Instituto Agronômico do Paraná na Estação Experimental de Paranavaí utilizando-se 36 tourinhos mestiços, com 16 a 20 meses de idade e com peso inicial de $398 \pm 10 \mathrm{~kg}$, oriundos do programa de cruzamento da estação.

Os animais foram alojados em baias individuais, com acesso a cocho de alimentação e água. Foram alimentados duas vezes ao dia ( 9 h e 15 h) com três dietas (Tabela 1): silagem de sorgo $+1,0 \%$ de concentrado, cana-de-açúcar picada $+1,0 \%$ de concentrado e cana-de-açúcar picada + $1,2 \%$ de concentrado, calculada com base no peso vivo (PV) em matéria seca, reajustado a cada 28 dias após a pesagem dos animais, e o volumoso fornecido à vontade. O concentrado foi formulado à base de farelo de soja, milho, ureia, calcário e sal branco. A dieta-base (silagem de sorgo) foi calculada para que tivesse em torno de $12 \%$ de proteína bruta (PB) e 70\% de nutrientes digestíveis totais (NDT). Os tratamentos com cana-de-açúcar receberam o mesmo concentrado da dieta-base, esperando-se que o tratamento cana-de-açúcar $+1,2 \%$ de concentrado apresentasse os mesmos teores de PB e NDT que a dietabase e o tratamento cana-de-açúcar $+1,0 \%$ de concentrado em condições intermediárias, sem comprometer o desempenho dos animais.

A duração do confinamento, de 27 de julho a 8 de novembro de 2006, totalizou 104 dias após período de 15 dias de adaptação. Os animais foram pesados, após jejum de 12 horas, no início e fim do período experimental, com pesagens intermediárias a cada 28 dias.

Tabela 1 - Composição das dietas utilizadas, com base na matéria seca

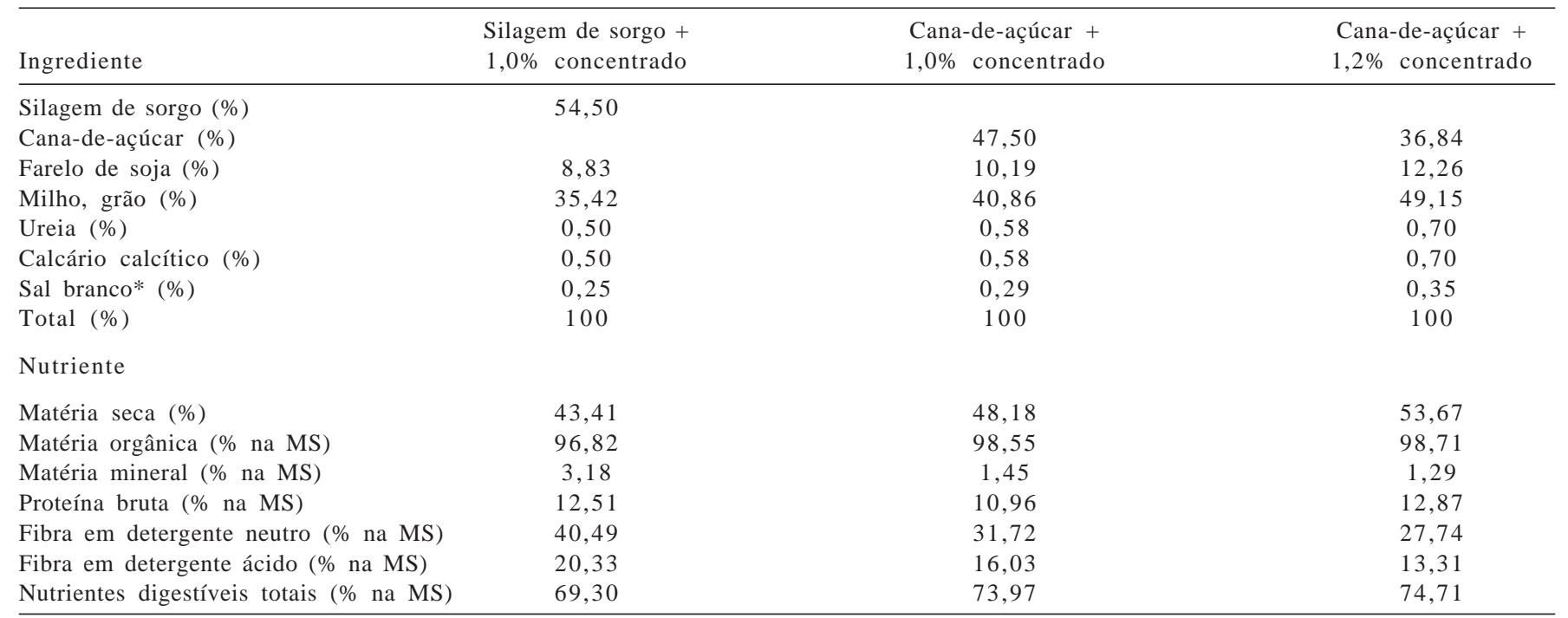

*Adicionado de microelementos, composição por kg do produto: Zn, 5.000 mg; Cu, 2.000 mg; Co, 30 mg; Se, 67 mg; I, 155 mg; e Na, 387 g. 
O consumo dos alimentos foi registrado diariamente por meio da pesagem da quantidade fornecida e das sobras do dia anterior. Foram determinados os teores de matéria seca (MS), matéria mineral (MM) e proteína bruta (PB) segundo as metodologias descritas por AOAC (1990); fibra em detergente neutro (FDN) e fibra em detergente ácido (FDA), de acordo com Goering \& Van Soest (1970), e nutrientes digestíveis totais (NDT) calculado conforme descrito por Chandler (1990) para gramíneas e silagem de grãos: \%NDT $=105,2-0,68(\% F D N)$ e para grãos: $\% \mathrm{NDT}=81,41-(0,6 \times \% \mathrm{FB})$, em que $\% \mathrm{FB}=\% \mathrm{FDA} \times 0,8$.

Foram determinados a ingestão de matéria seca, em $\mathrm{kg} / \mathrm{dia}$, em porcentagem do peso vivo e expressa por unidade do tamanho metabólico em g MS/PV ${ }^{0,75}$, a ingestão de proteína bruta, de fibra em detergente neutro e de nutrientes digestíveis totais em $\mathrm{kg} / \mathrm{dia}$, o peso vivo final e o peso de carcaça quente em $\mathrm{kg}$, o rendimento de carcaça, o ganho médio diário em kg, a conversão alimentar, a eficiência alimentar, o índice bionutricional (IBN), a porcentagem de osso, de músculo e de gordura e a espessura de gordura subcutânea. O índice bionutricional foi obtido a partir da primeira variável canônica pela análise de variância multivariada da ingestão de matéria seca e do ganho médio diário,conforme descrito por Detmann et al. (2005).

$\mathrm{O}$ abate foi realizado segundo a rotina do frigorífico comercial. O rendimento de carcaça foi obtido a partir do peso vivo em jejum do animal antes do envio ao frigorífico e do peso da carcaça quente determinado ao abate. A determinação da espessura da gordura de cobertura subcutânea (EGS) foi efetuada na região do corte entre a 12 a e $13^{\underline{a}}$ costelas, acima do músculo Longissimus dorsi, com o auxílio de um paquímetro, calculando-se a média de duas determinações por carcaça.

As porcentagens de osso, de músculo e de gordura na carcaça foram determinadas utilizando-se a secção do músculo Longissimus dorsi correspondente a $10^{\underline{a}}$, $11^{\underline{a}}$ e $12^{\underline{a}}$ costelas, cujo corte foi obtido segundo metodologia descrita por Hankins \& Howe (1946). A partir do segmento obtido realizou-se a separação física do osso, músculo e gordura, com a pesagem separada de cada componente.

As respectivas porcentagens obtidas nessa secção foram colocadas nas equações de regressão obtidas por Müller et al. (1973), citadas por Moletta (1990), para determinação das respectivas porcentagens nas costelas. Transformando esses dados correspondentes à 9a, $10^{\underline{a}}$ e $11^{\underline{a}}$ costelas, obtém-se: $\% \mathrm{M}=6,292+0,910 \mathrm{X}_{1} ; \% \mathrm{O}=2,117$ + $0,860 X_{2}$ e \% G $=1,526+0,913 X_{3}$, em que $X_{i}$ representa, respectivamente, os percentuais de músculo, osso e gordura, correspondentes.
Os percentuais correspondentes à $9^{\underline{a}}, 10^{\underline{a}}$ e $11^{\underline{a}}$ costelas foram inseridos nas equações de regressão, segundo Hankins \& Howe (1946), obtendo-se os percentuais de músculo (PM), osso (PO) e gordura (PG) nas carcaças estudadas, em que: $\mathrm{PM}=15,56+0,81 \mathrm{M} ; \mathrm{PO}=4,30+0,61 \mathrm{O}$ e $P G=3,06+0,82 \mathrm{G}$, sendo $\mathrm{M}$, O e $\mathrm{G}$, respectivamente, os valores de músculo, osso e gordura encontrados pelas equações de Muller et al. (1973).

O delineamento experimental utilizado foi o inteiramente casualizado, com três tratamentos e 12 repetições, considerando o peso vivo inicial covariável na análise estatística. Todas as características em estudo foram submetidas ao teste de normalidade Shapiro-Wilk. A característica EGS não obedeceu à distribuição normal e foi analisada utilizando-se a metodologia de modelos lineares generalizados, com distribuição Gama e função de ligação Recíproca, pelo procedimento GENMOD. Para testar as hipóteses, foi utilizado o teste de Wald. As médias foram comparadas pelo procedimento Least Square Means (SAS, 2001). As demais características apresentaram distribuição normal e foram submetidas à análise de variância e as médias, comparadas pelo teste Tukey a 5\% de probabilidade, pelo procedimento Least Square Means (SAS, 2001).

\section{Resultados e Discussão}

O peso vivo final foi maior $(\mathrm{P}<0,05)$ nos animais alimentados com silagem de sorgo (Tabela 2), com média de $567,41 \mathrm{~kg}$. Os pesos observados foram superiores aos relatados por Pereira et al. (2006) para bovinos Holandês $\times$ Zebu alimentados com silagem de sorgo e diferentes proporções de concentrado, médias de 434,88 e 523,08 kg respectivamente, para peso vivo inicial e final.

Os valores elevados do peso vivo final, em comparação aos de outros experimentos, podem ser explicados pela composição genética dos animais, produtos de cruzamento entre raças zebuínas e europeias continentais de elevado peso adulto resultando em progênies de peso adulto mais elevado, além disso, o fato de os animais não serem castrados, acentuou o desenvolvimento muscular em detrimento à deposição de gordura, o que também contribuiu para o aumento do peso ao abate (Abrahão et al., 2005).

O ganho médio diário foi maior $(\mathrm{P}<0,05)$ nos animais alimentados com silagem de sorgo e $1,0 \%$ de concentrado (Tabela 2) e muito superior ao ganho médio diário obtido por Neumann et al. (2001) com dietas com concentrado e silagem de sorgo forrageiro $(0,943 \mathrm{~kg} / \mathrm{dia})$ ou silagem de sorgo de duplo propósito (1,163 kg/dia), por Pereira et al. (2006) para dietas com relação volumoso:concentrado 
variando de 80:20 a 35:65 (1,25 a 1,54 kg/dia) e por Vargas Jr. et al. (2003) para bovinos mestiços alimentados com silagem de sorgo e concentrado (1,497 kg/dia). O maior ganho médio diário, comparado aos dados da literatura, provavelmente foi ocasionado pela composição genética dos animais, associada ao fato de os animais não serem castrados e as dietas serem balanceadas e ajustadas a cada 28 dias para não comprometer o desempenho dos animais. Além disso, as dietas apresentaram no máximo $54,50 \%$ de volumoso.

A conversão alimentar e a eficiência alimentar não diferiram $(\mathrm{P}>0,05)$ entre as dietas, entretanto o índice bionutricional (IBN) foi maior $(\mathrm{P}<0,05)$ para os animais alimentados com silagem de sorgo. O índice bionutricional foi determinado a partir dos coeficientes gerados pela análise da primeira variável canônica da ingestão de matéria seca e do ganho médio diário, que apresentaram coeficientes no autovetor de 0,99918 e 0,94886, respectivamente. O maior autovalor, ou seja, a importância relativa da primeira variável canônica, foi de 99,21\%. O autovalor confirma as inferências realizadas por Detmann et al. (2005) de que o índice bionutricional garante máxima discriminação entre os grupos experimentais e permite a identificação de diferenças significativas, não-perceptíveis pela conversão e eficiência alimentar, o que parece ser consequência da incorporação de características de intensidade de produção, associadas à aplicação do índice bionutricional.

O peso de carcaça, segundo Abrahão et al. (2005), é uma característica importante, associada diretamente ao valor comercial do animal, uma vez que o frigorífico remunera o produtor pelo peso de carcaça dos animais, reduzindo o valor pago por aquelas que não atingem o peso mínimo de $230 \mathrm{~kg}$. Os autores relatam que, como os custos operacionais por animal abatido são praticamente iguais, os frigoríficos preferem os animais com peso vivo e de carcaça elevados, além disso, supermercados e açougues ainda buscam músculos de maior tamanho, que estão associados a carcaças de maior peso, visando atender a preferência do consumidor.

Os animais alimentados com silagem de sorgo apresentaram maior peso de carcaça quente $(\mathrm{P}<0,05)$ em comparação aos alimentados com cana-de-açúcar, corroborando os resultados obtidos para o peso vivo final, o ganho médio diário e o índice bionutricional. O rendimento de carcaça não diferiu entre os animais alimentados com silagem de sorgo ou com cana-de-açúcar. O rendimento de carcaça (média 54,42\%) foi semelhante aos de $54,82 \%$ e $54,26 \%$ obtidos em touros mestiços por Abrahão et al. (2005) e Perotto et al. (2000), respectivamente, e ao de $54,85 \%$, obtido por Ezequiel et al. (2006) em animais Nelore. Valores compatíveis, segundo Abrahão et al. (2005), com os observados para animais abatidos em frigoríficos comerciais que realizam toillete mais rigorosa, reduzindo o rendimento da carcaça em relação a abatedouros de universidades e instituições de pesquisa.

A ingestão de matéria seca, expressa nas diferentes formas, e a ingestão de proteína bruta, de fibra em detergente neutro e de nutrientes digestíveis totais foram maiores $(\mathrm{P}<0,05)$ para os animais alimentados com silagem de sorgo (Tabela 3), comprovando os efeitos da cana-de-açúcar em limitar o consumo e a produção animal.

De acordo com Magalhães et al. (2006), independentemente da estratégia de alimentação utilizada, forragens de qualidades diferentes afetam a ingestão de MS que é influenciada pela digestibilidade da fibra do alimento. A menor ingestão pelos animais alimentados com cana-deaçúcar pode ser explicada pelo fato de apresentar maior fração indigestível da fibra, portanto, é negativamente correlacionada com a ingestão de matéria seca. Quando se avaliaram somente os animais alimentados com cana-deaçúcar, aqueles que receberam maior porcentagem de concentrado na dieta apresentaram maior ingestão de matéria seca, de proteína bruta e de nutrientes digestíveis totais.

Tabela 2 - Peso vivo final, peso de carcaça quente, rendimento de carcaça, ganho médio diário, conversão alimentar, eficiência alimentar e índice bionutricional de tourinhos mestiços terminados em confinamento com dietas com cana-de-açúcar e concentrado em substituição à silagem de sorgo

\begin{tabular}{|c|c|c|c|c|c|}
\hline & \multicolumn{3}{|c|}{ Dieta } & \multirow[t]{2}{*}{ Valor-P } & \multirow[t]{2}{*}{ CV (\%) } \\
\hline & $\begin{array}{l}\text { Silagem de sorgo }+ \\
1,0 \% \text { concentrado }\end{array}$ & $\begin{array}{l}\text { Cana-de-açúcar }+ \\
1,0 \% \text { concentrado }\end{array}$ & $\begin{array}{l}\text { Cana-de-açúcar }+ \\
1,2 \% \text { concentrado }\end{array}$ & & \\
\hline Peso de carcaça quente $(\mathrm{kg})$ & $309,66 \pm 4,411 \mathrm{a}$ & $294,57 \pm 4,174 b$ & $296,36 \pm 4,170 b$ & 0,0410 & 4,80 \\
\hline Rendimento de carcaça (\%) & $54,51 \pm 0,487$ & $54,45 \pm 0,460$ & $54,29 \pm 0,460$ & 0,9470 & 2,92 \\
\hline Ganho médio diário (kg) & $1,68 \pm 0,065 a$ & $1,41 \pm 0,062 b$ & $1,46 \pm 0,062 b$ & 0,0126 & 14,05 \\
\hline Índice bionutricional & $13,12 \pm 0,222 \mathrm{a}$ & $10,29 \pm 0,210 \mathrm{c}$ & $11,29 \pm 0,210 \mathrm{~b}$ & $<0,0001$ & 6,30 \\
\hline
\end{tabular}

Médias seguidas de letras diferentes na linha diferem entre si $(\mathrm{P}<0,05)$ pelo teste Tukey. 
O baixo consumo de MS para dietas à base de canade-açúcar encontrados em vários estudos com cana-deaçúcar e silagem de milho (Magalhães et al., 2004; Mendonça et al., 2004; Costa et al., 2005) está relacionado à baixa digestibilidade da FDN da cana-de-açúcar (Oliveira et al., 2001; Mendonça et al., 2004; Costa et al., 2005; Magalhães et al., 2006), à baixa taxa de passagem e ao alto tempo de retenção da cana, justificado pela maior fração indigestível da fibra, provavelmente pelo fato de conter mais lignina em sua parede celular (Pereira et al., 2000), e não somente ao teor da FDN na dieta, uma vez que nesses trabalhos com silagem de milho e com cana-de-açúcar, os teores de FDN eram maiores nas dietas com silagem de milho, que também resultavam em maior consumo. Fato semelhante foi observado neste experimento para a silagem de sorgo, que apresenta maior digestibilidade da FDN (Rodrigues et al., 2002; Pereira et al., 2006), com cana-de-açúcar.
O fato de os animais serem jovens e não-castrados, explicaria a alta porcentagem de músculo (média de 66,42\%) e a baixa porcentagem de gordura (média de 20,02\%) (Tabela 4), que, segundo Di Marco, citado por Abrahão et al. (2005), estaria abaixo do recomendado para animais acabados, que seria de 23 a 25\% de gordura na carcaça.

Abrahão et al. (2005), em pesquisa com tourinhos nãocastrados mestiços, obtiveram porcentagem média de gordura de $20,85 \%$ e sugeriram que maiores porcentagens de gordura na carcaça poderiam ser obtidas com animais alimentados com maiores níveis de energia nas dietas. Owens et al. (1993), avaliando os fatores que alteram o crescimento e desenvolvimento de ruminantes, afirmaram que, embora a taxa máxima de crescimento seja ajustada geneticamente, os fatores nutritivos e hormonais podem limitar a taxa de crescimento, alterando o tamanho à maturidade, reduzindo ou aumentando o conteúdo de gordura na carcaça. Assim, o nível de energia na dieta e os

Tabela 3 - Ingestão de matéria seca, proteína bruta, fibra em detergente neutro e nutrientes digestíveis totais em tourinhos mestiços em confinamento alimentados com dietas com cana-de-açúcar e concentrado em substituição à silagem de sorgo

\begin{tabular}{|c|c|c|c|c|c|}
\hline \multirow[b]{2}{*}{ Ingestão } & \multicolumn{3}{|c|}{ Dieta } & \multirow[t]{2}{*}{ Valor-P } & \multirow[t]{2}{*}{ CV (\%) } \\
\hline & $\begin{array}{l}\text { Silagem de sorgo }+ \\
1,0 \% \text { concentrado }\end{array}$ & $\begin{array}{l}\text { Cana-de-açúcar }+ \\
1,0 \% \text { concentrado }\end{array}$ & $\begin{array}{l}\text { Cana-de-açúcar }+ \\
1,2 \% \text { concentrado }\end{array}$ & & \\
\hline Matéria seca (kg/dia) & $11,53 \pm 0,203 a$ & $8,96 \pm 0,192 c$ & $9,92 \pm 0,192 b$ & $<0,0001$ & 6,56 \\
\hline Matéria seca (\% PV) & $2,46 \pm 0,043 a$ & $1,96 \pm 0,040 c$ & $2,16 \pm 0,040 b$ & $<0,0001$ & 6,37 \\
\hline Matéria seca (g MS/PV 0,75 ) & $114,20 \pm 1,986 a$ & $90,44 \pm 1,880 \mathrm{c}$ & $99,84 \pm 1,878 b$ & $<0,0001$ & 6,41 \\
\hline Proteína bruta (kg/dia) & $1,44 \pm 0,024 a$ & $0,98 \pm 0,023 c$ & $1,28 \pm 0,023 b$ & $<0,0001$ & 6,41 \\
\hline Fibra em detergente neutro (kg/dia) & $4,40 \pm 0,071 a$ & $2,58 \pm 0,067 b$ & $2,48 \pm 0,067 b$ & $<0,0001$ & 7,42 \\
\hline Nutrientes digestíveis totais (kg/dia) & $7,91 \pm 0,144 a$ & $6,62 \pm 0,136 c$ & $7,34 \pm 0,136 b$ & $<0,0001$ & 6,46 \\
\hline
\end{tabular}

Médias seguidas de letras diferentes na linha diferem entre si $(\mathrm{P}<0,05)$ pelo teste Tukey.

Tabela 4 - Porcentagens de osso, músculo e gordura e espessura de gordura subcutânea de tourinhos mestiços terminados em confinamento com dietas com cana-de-açúcar e concentrado em substituição à silagem de sorgo

\begin{tabular}{|c|c|c|c|c|c|}
\hline & \multicolumn{3}{|c|}{ Dieta } & \multirow[t]{2}{*}{ Valor-P } & \multirow[t]{2}{*}{ CV (\%) } \\
\hline & $\begin{array}{l}\text { Silagem de sorgo }+ \\
1,0 \% \text { concentrado }\end{array}$ & $\begin{array}{l}\text { Cana-de-açúcar + } \\
1,0 \% \text { concentrado }\end{array}$ & $\begin{array}{l}\text { Cana-de-açúcar }+ \\
1,2 \% \text { concentrado }\end{array}$ & & \\
\hline Músculo $(\%)^{1}$ & $66,30 \pm 0,627$ & $65,94 \pm 0,597$ & $67,03 \pm 0,620$ & 0,4409 & 3,09 \\
\hline Osso $(\%)^{1}$ & $13,59 \pm 0,273$ & $14,44 \pm 0,260$ & $14,30 \pm 0,270$ & 0,0777 & 6,34 \\
\hline Gordura $(\%)^{1}$ & $20,79 \pm 0,646$ & $20,19 \pm 0,614$ & $19,10 \pm 0,638$ & 0,1846 & 10,56 \\
\hline Gordura subcutânea $(\mathrm{mm})^{2}$ & $5,41 \pm 0,034^{3}$ & $4,10 \pm 0,036^{3}$ & $3,79 \pm 0,039^{3}$ & 0,0737 & - \\
\hline
\end{tabular}

Médias seguidas de letras diferentes na linha diferem entre si $(\mathrm{P}<0,05)$, pelo testes Tukey ${ }^{1}$ e qui-quadrado ${ }^{2}$.

${ }^{3}$ Erro-padrão da estimativa.

fatores hormonais podem ter sido responsáveis pela menor porcentagem de gordura.

Os valores observados para espessura de gordura subcutânea neste trabalho (Tabela 4) estão na faixa preconizada pelos frigoríficos, entre 3 e $6 \mathrm{~mm}$, sendo semelhante entre os tratamentos e compatível com o nível de energia da dieta.

\section{Conclusões}

Apesar de não influenciar as proporções de músculo, osso e gordura na carcaça, a substituição total da silagem de sorgo pela cana-de-açúcar reduz o desempenho de tourinhos mestiços na fase de terminação em confinamento, mesmo com maior nível de concentrado na dieta. 


\section{Referências}

ABRAHÃO, J.J.S.; PRADO, I.N.; PEROTTO, D. et al. Características de carcaças e da carne de tourinhos submetidos a dietas com diferentes níveis de substituição do milho por resíduo úmido da extração da fécula de mandioca. Revista Brasileira de Zootecnia, v.34, n.5, p.1640-1650, 2005.

ASSOCIATION OF OFFICIAL ANALYTICAL CHEMISTS. OFFICIAL METHODS OF ANALYSIS - AOAC. 15.ed. Arlington: Virgínia. v.1, 1990. 684p.

COSTA, M.G.; CAMPOS, J.M.S.; VALADARES FILHO, S.C. et al. Desempenho produtivo de vacas leiteiras alimentadas com diferentes proporções de cana-de-açúcar e concentrado ou silagem de milho na dieta. Revista Brasileira de Zootecnia, v.34, n.6, p.2437-2445, 2005 (supl.).

DETMANN, E.; CECON, P.R.; ANDREOTTI, M.O. et al. Application of the first canonical variable in the evaluation of animal production. Revista Brasileira de Zootecnia, v.34, n.6, p.2417-2426, 2005 (supl.).

EZEQUIEL, J.M.B.; GALATI, R.L.; MENDES, A.R. et al. Desempenho e características de carcaça de bovinos Nelore em confinamento alimentados com bagaço de cana-de-açúcar e diferentes fontes energéticas. Revista Brasileira de Zootecnia, v.35, n.5, p.2050-2057, 2006.

GOERING, H.K.; VAN SOEST, P.J. Forage fiber analyses; apparatus, reagents, procedures and some applications. Washington: USDA/Agricultural Research Service, 1970. 19p.

HANKINS, O.G.; HOWE, P.E. Estimation of the composition of beef carcasses and cuts. Washington, D.C.: United States Department of Agriculture, 1946. p.1-20. (Technical Bulletin USDA, 926).

MAGALHÃES, A.L.R.; CAMPOS, J.M.S.; CABRAL, L.S. et al. Canade-açúcar em substituição à silagem de milho em dietas para vacas em lactação: parâmetros digestivos e ruminais. Revista Brasileira de Zootecnia, v.35, n.2, p.591-599, 2006.

MAGALHÃES, A.L.R.; CAMPOS, J.M.S.; VALADARES FILHO, S.C. et al. Cana-de-açúcar em substituição à silagem de milho em dietas para vacas em lactação: desempenho e viabilidade econômica. Revista Brasileira de Zootecnia, v.33, n.5, p.1292-1302, 2004.

MENDONÇA, S.S.; CAMPOS, J.M.S.; VALADARES FILHO, S.C. et al. Consumo, digestibilidade aparente, produção e composição do leite e variáveis ruminais em vacas leiteiras alimentadas com dietas à base de cana-de-açúcar. Revista Brasileira de Zootecnia, v.33, n.2, p.481-492, 2004.

MOLETTA, J.L. Desempenho em confinamento e características de carcaça e da carne de diferentes grupos genéticos de bovídeos. 1990. 110f. Dissertação (Mestrado em Zootecnia) Universidade Federal de Santa Maria, Santa Maria.
MÜLLER, L.; MAXON, W.E.; PALUER, A.Z. et al. Evaluacíon de técnicas para determinar la composición de la canal. In: ASOCIACIÓN LATINOAMERICANA DE PRODUCCIÓN ANIMAL - ALPA, 4., 1973, Guadalajara. Anais... Guadalajara: ALPA, 1973. (sn).

NEUMANN, M.; RESTLE, J.; ALVES FILHO, D.C. et al. Avaliação da silagem de diferentes híbridos de sorgo (Sorghum bicolor L. Moench) por meio do desempenho de novilhos de corte confinados. Revista Brasileira de Zootecnia, v.30, n.6, p.2099-2109, 2001 (supl.).

OLIVEIRA, M.D.S.; CASAGRANDE, A.A.; OLIVEIRA, E.F.S. Efeito da digestibilidade in vitro de variedades de cana-deaçúcar sobre seu valor como alimento para bovinos. ARS Veterinária, v.17, n.3, p.238-243, 2001.

OWENS, F.N.; DUBESKI, P.; HANSON, C.F. Factors that alter growth and development of ruminants. Journal of Animal Science, v.71, p.3138-3150, 1993.

PEREIRA, D.H.; PEREIRA, O.G.; VALADARES FILHO, S.C. et al. Consumo, digestibilidade dos nutrientes e desempenho de bovinos de corte recebendo silagem de sorgo (Sorghum bicolor (L.) Moench) e diferentes proporções de concentrado. Revista Brasileira de Zootecnia, v.35, n.1, p.282-291, 2006.

PEREIRA, E.S.; QUEIROZ, A.C.; PAULINO, M.F. et al. Determinação das frações protéicas e de carboidratos e taxas de degradação in vitro da cana-de-açúcar, da cama de frango e do farelo de algodão. Revista Brasileira de Zootecnia, v.29, n.6, p.1887-1893, 2000.

PEROTTO, D.; ABRAHÃO, J.J.S.; MOLETTA, J.L. Características quantitativas de carcaça de bovinos Zebu e de cruzamentos Bos taurus $\times$ Zebu. Revista Brasileira de Zootecnia, v.29, n.6, p.2019-2029, 2000 (supl. 1).

PINTO, A.P.; PEREIRA, E.S.; MIZUBUTI, I.Y. Características nutricionais e formas de utilização da cana-de-açúcar na alimentação de ruminantes. Semina: Ciências Agrárias, v.24, n.1, p.73-84, 2003.

RODRIGUES, P.H.M.; SENATORE, A.L.; LUCCI, C.S. et al. Valor nutritivo da silagem de sorgo tratada com inoculantes enzimomicrobianos, Acta Scientiarum, v.24, n.4, p.1141-1145, 2002.

STATISTICAL ANALYSIS SYSTEM - SAS. User's guide: statistics. Cary: SAS Institute, 2001. (CD-ROM).

VARGAS JR., F.M.; SANCHEZ, L.M.B.; PASCOAL, L.L. et al. Desempenho de bezerros de corte alimentados com diferentes fontes protéicas associadas à silagem de sorgo colhida em duas alturas de corte. Revista Brasileira de Zootecnia, v.32, n.3, p.690-698, 2003.

ZAGO, C.P. Silagem de sorgo. In: SIMPÓSIO SOBRE NUTRIÇÃO DE BOVINOS: ALIMENTAÇÃO SUPLEMENTAR, 7., 1999. Anais... Piracicaba: Fundação de Estudos Agrários Luiz de Queiroz, 1999. p.47-68. 